\title{
Long term survival and cure after childhood cancer
}

\author{
M M HAWKINS \\ Childhood Cancer Research Group, Radcliffe Infirmary, Oxford
}

SUMMARY Investigations of long term survival and evidence concerning cure among children surviving at least three years after most of the more common childhood cancers treated in Britain between 1960 and 1981 are reported. The results indicate striking improvements in survival beyond three years for many childhood tumours over this period. For most childhood tumours considered over $80 \%$ of those who had survived at least three years were alive 10 years later. Comparison of mortality observed among survivors with that expected for the general population showed evidence of cure among those who had survived at least three years after non-Hodgkin lymphomas and non-genetic retinoblastoma. Survivors of other tumours, with sufficient cases surviving beyond 10 years to examine excess mortality, rarely experienced an excess that exceeded one extra death per 100 survivors per year. Children who had survived at least 10 years after other embryonal tumours, soft tissue sarcomas, or osteosarcoma never experienced an excess mortality exceeding one extra death per 200 survivors per year.

Relatively little has been published on long term survival and evidence of cure after childhood malignant disease. Reasons for this are the rarity of the disease (an overall annual incidence of 1/10000 below age 15 in Britain) and the fact that substantial improvements in short term survival have occurred only relatively recently for some of the more common diseases, including leukaemia. Large numbers of survivors are required for a satisfactory analysis of long term mortality and examination of evidence of associations between survival and possible explanatory factors like sex of survivor, or age and calendar year when diagnosed. Data are presented relating to almost all those who survived at least three years after childhood cancer and who had been treated in Britain between 1960 and 1981 inclusive. This provided sufficient numbers to enable a reliable analysis.

To obtain a greater understanding of curability we shall examine the specific causes of death in a further paper.

\section{Patients and methods}

\section{ASCERTAINMENT OF CASES}

The Childhood Cancer Research Group is routinely notified of tumours registered under the National Cancer Registration Scheme occurring in children aged under 15 and diagnosed in 1962 or later. This provides, within the limits of completeness of cancer registration, a population based series of childhood cancer cases occurring in Britain. Childhood cancer registration is estimated to include over $90 \%$ of incident cases. ${ }^{12}$ In addition 2000 children who had survived at least three years, and who had been diagnosed between 1940 and 1961, were assembled from particular treatment centres where it was known that a complete (and therefore unbiased) list of cases was available.

Cases were included if diagnosed before 1982 and known to have survived at least three years. Follow up in relation to death was achieved by 'flagging' survivors at the National Health Service Central Registers, Southport and Edinburgh. Tumours were classified using a recently published scheme. ${ }^{34}$

To be included in the analysis histological verification of each diagnosis was required except that for: (a) retinoblastoma where 56 of the total of 874 diagnoses were based on observation at operation; (b) central nervous system tumours where 52 of the total of 2077 diagnoses were based on radiology, scans, or observation at operation; (c) neuroblastoma where five of the total of 431 diagnoses were based on biochemistry; and (d) craniopharyngioma where 23 of the total of 220 diagnoses were based on biochemistry or observation at operation. Of the 2450 diagnoses of leukaemia 87 were based on blood counts only.

\section{STATISTICAL METHODS}

Survival curves and life tables were constructed 
using standard techniques decribed by Peto et $a l^{5}$; comparison of life tables was carried out using standard tests. ${ }^{5}$ Mortality occurring during different periods of follow up after diagnosis was compared with that expected for the general population of Britain. Analysis was carried out for England and Wales, and separately for Scotland, and then the results combined for Britain. Observed and expected numbers of deaths were compared assuming that the observed number approximate a Poisson distribution with mean equal to the corresponding expected number. Tests of significance were based on exact Poisson methods.

\section{Results}

There were 11449 children who had survived at least three years who were eligible for analysis. Table 1 gives the number of these survivors after each tumour type with sufficient cases to examine variation in mortality with follow up and possible associations with explanatory factors. Large variations in long term survival prospects are shown in table 1 . Over $60 \%$ of children who survived at least three years were alive 10 years later except those diagnosed with medulloblastoma or Ewing's tumour. For most tumours over $80 \%$ of these children were alive 10 years later.

The number of children who had survived at least three years available for analysis was affected both by incidence and survival. Although there was some evidence of changes in incidence of some tumour types during the study period, ${ }^{67}$ much greater changes in survival have been observed. ${ }^{78}$

Variations in survival by sex of survivor, calendar year of diagnosis, and age at diagnosis are summarised in table 2. Table 3 summarises the results of comparing all causes of mortality observed among survivors with that expected from the general population. The observed and expected numbers of deaths were considered in several follow up intervals at varying times from diagnosis. For each tumour type, and for those follow up intervals with at least 100 survivors alive on entry, are given the numbers entering each follow up interval, the observed and expected numbers of deaths, the Poisson probability of the observed number of deaths given those expected, and finally a measure of the excess mortality among survivors.

Survivors were regarded as cured when the mortality of the group was statistically indistinguishable from that expected. There are known problems with this approach, as described below, but it does provide insight into the risk of dying compared with members of the general population of a similar age, sex, and date of birth. Using this as a formal definition of cure, then cure may be considered to have been reached when the Poisson one tailed $p$ value exceeds some specified arbitrary value, 0.05 for example. We only assessed evidence of cure if the expected number of deaths beyond a specified follow up time was at least two.

Table 1 Long term survival among children surviving at least three years

\begin{tabular}{llll}
\hline Diagnosis & $\begin{array}{l}\text { No of children surviving } \\
\text { at least three years }\end{array}$ & $\begin{array}{l}\text { (\%) Still alive 10 years } \\
\text { after survival to } \\
\text { three years }\end{array}$ & Standard error (\%) \\
\hline Acute lymphocytic leukaemia & 2335 & 63 & 1 \\
Hodgkin's disease & 948 & 74 & 2 \\
Non-Hodgkin's lymphomas & 507 & 85 & 2 \\
Neuroblastoma & 431 & 89 & 2 \\
Wilms' tumour & 930 & 94 & 1 \\
Retinoblastoma: & 399 & 93 & 1 \\
$\quad$ Genetic & 475 & 100 & 0 \\
$\quad$ Non-genetic & 480 & 56 & 2 \\
Medulloblastoma & 261 & 68 & 3 \\
Ependymoma & 599 & 88 & 1 \\
Juvenile astrocytoma & 737 & 82 & 3 \\
Other astrocytomas & 196 & 57 & 4 \\
Osteosarcoma & 191 & 90 & 2 \\
Ewing's tumour & 221 & 83 & 2 \\
Fibrosarcoma & 262 & 96 & 2 \\
Rhabdomyosarcoma & 121 & 94 & \\
Malignant testicular germ cell & 113 & & \\
Malignant ovarian germ cell & 2226 & & \\
Other histological types & & & \\
\hline
\end{tabular}


Table 2 Variation in survival beyond three years by sex, calendar year, and age at diagnosis

\begin{tabular}{|c|c|c|c|c|}
\hline \multirow[t]{2}{*}{ Diagnosis } & \multicolumn{4}{|c|}{ Summary of statistically significant associations } \\
\hline & Sext & $\begin{array}{l}\text { Calendar year } \\
\text { at diagnosis } \ddagger \\
\text { (before } 1962, \\
1962-70, \\
\text { after 1970) }\end{array}$ & $\begin{array}{l}\text { Age at diagnosis } \\
\text { in years } \ddagger \\
(0-4, \\
5-9 \\
10-14)\end{array}$ & $\begin{array}{l}\text { Alternative } \\
\text { grouping of age§ } \\
\text { (years) }\end{array}$ \\
\hline Acute lymphocytic leukacmia & $<0 \cdot 0001(\mathrm{~F})$ & $<0.0001 \|$ & * & \\
\hline Hodgkin's disease & * & $<0.0001 \|$ & $0 \cdot 0026$ I & $0-10,11-12,13-14$ \\
\hline Non-Hodgkin lymphomas & * & * & ${ }^{*}$ & $0-8,9-11,12-14$ \\
\hline Neuroblastoma & * & * & $<0.0001 \pi$ & $0,1-2,3-14$ \\
\hline Wilms' tumour & * & $0 \cdot 0124 \|$ & $0 \cdot 0004 \pi$ & $0-1,2-3,4-14$ \\
\hline \multicolumn{5}{|l|}{ Retinoblastoma: } \\
\hline Genetic & * & * & * & $0,1,2-14$ \\
\hline Non-genetic & $*$ & $*$ & $(0 \cdot 0254)^{* *}$ & $0,1,2-14$ \\
\hline Medulloblastoma & * & $0 \cdot 0012 \|$ & 0.00909 & \\
\hline Ependymoma & $0.0274(\mathrm{~F})$ & $0 \cdot 0364 \|$ & $0.0492 \|$ & \\
\hline Juvenile astrocytoma & $*$ & * & $0.0016 \|$ & \\
\hline Other astrocytomas & $*$ & $0 \cdot 0012 \|$ & $0 \cdot 0274 \|$ & \\
\hline Osteosarcoma & $*$ & * & * & $0-10,11-12,13-14$ \\
\hline Ewing's tumour & * & * & * & $0-8,9-11,12-14$ \\
\hline Fibrosarcoma & $*$ & $*$ & $*$ & \\
\hline Rhabdomyosarcoma & $0.0140(\mathrm{M})$ & * & * & $0-2,3-5,6-14$ \\
\hline Malignant testicular germ cell & * & * & * & $0,1,2-14$ \\
\hline Malignant ovarian germ cell & $*$ & $0 \cdot 0336$ & ${ }^{*}$ & $0-10,11-12,13-14$ \\
\hline
\end{tabular}

*The relevant test was not significant at 0.05 level, two tailed test.

$\dagger(M)$ or $(F)$ indicates sex with greater survival.

$\ddagger$ The $\mathrm{p}$ values result from a test for trend. For age at diagnosis there was no evidence of heterogeneity in the absence of a significant trend. $\S$ The categories of subdivision for age at diagnosis were $0-4,5-9,10-14$ except where indicated to the contrary in final column.

||Survival increases with increasing calendar year of diagnosis or age at diagnosis.

TSurvival decreases with increasing age at diagnosis.

${ }^{* *} p$ Value in parentheses is unreliably estimated and is ignored in the text.

Table 3 Comparison of observed and expected mortality among children surviving at least three years

\begin{tabular}{|c|c|c|c|c|c|c|c|c|}
\hline & \multicolumn{8}{|c|}{ Years from diagnosis } \\
\hline & \multicolumn{5}{|l|}{$3-4(3-)^{*}$} & \multicolumn{3}{|c|}{$5-9(\text { or } 5-)^{*}$} \\
\hline & $\begin{array}{l}\text { No of } \\
\text { survivors }\end{array}$ & $\begin{array}{l}\text { Observed } \\
(O)\end{array}$ & $\begin{array}{l}\text { Expected } \\
\text { (E) }\end{array}$ & $\begin{array}{l}\text { Poisson } \\
\text { probability } \\
(p)^{\dagger}\end{array}$ & $\begin{array}{l}\text { Excess } \\
\text { mortality } \neq\end{array}$ & $\begin{array}{l}\text { No of } \\
\text { survivors }\end{array}$ & $\begin{array}{l}\text { Observed } \\
(O)\end{array}$ & $\begin{array}{l}\text { Expected } \\
(E)\end{array}$ \\
\hline Hodgkin's disease & 948 & 105 & $0 \cdot 9$ & $0 \cdot 000$ & $5 \cdot 8$ & 844 & 104 & $2 \cdot 0$ \\
\hline Non-Hodgkin lymphomas & 507 & 36 & $0 \cdot 5$ & $0 \cdot 000$ & $3 \cdot 6$ & 471 & 33 & $1 \cdot 1$ \\
\hline Neuroblastoma & 431 & 25 & $1 \cdot 6$ & 0.000 & $2 \cdot 8$ & 407 & 19 & 0.5 \\
\hline Wilms' tumour & 930 & 32 & 1.7 & 0.000 & 1.7 & 896 & 17 & $1 \cdot 2$ \\
\hline \multicolumn{9}{|l|}{ Retinoblastoma: } \\
\hline Genetic & 399 & 5 & $2 \cdot 0$ & 0.049 & $0 \cdot 4$ & 392 & 16 & $0 \cdot 6$ \\
\hline Non-genetic & 475 & 0 & $1 \cdot 0$ & $1 \cdot 000$ & $-0 \cdot 1$ & 472 & 0 & 0.7 \\
\hline Medulloblastoma & 480 & 111 & 0.4 & 0.000 & $13 \cdot 2$ & 368 & 75 & $0 \cdot 6$ \\
\hline Ependymoma & 261 & 43 & $0 \cdot 2$ & 0.000 & $9 \cdot 0$ & 219 & 28 & $0 \cdot 4$ \\
\hline Osteosarcoma & 196 & 29 & $0 \cdot 2$ & $0 \cdot 000$ & 7.9 & 167 & 14 & 0.4 \\
\hline Ewing's tumour & 191 & 56 & $0 \cdot 1$ & $0 \cdot 000$ & $17 \cdot 8$ & 135 & 24 & 0.5 \\
\hline Fibrosarcoma & 221 & 7 & $0 \cdot 4$ & $0 \cdot 000$ & $1 \cdot 5$ & 211 & 12 & $0 \cdot 5$ \\
\hline Rhabdomyosarcoma & 262 & 26 & $0 \cdot 3$ & $0 \cdot 000$ & $5 \cdot 3$ & 234 & 14 & $0 \cdot 3$ \\
\hline Malignant testicular germ cell & 121 & 3 & $0 \cdot 3$ & $0 \cdot 006$ & $1 \cdot 1$ & 117 & 1 & 0.8 \\
\hline Malignant ovarian germ cell & 113 & 4 & $0 \cdot 1$ & $0 \cdot 000$ & 1.8 & 108 & 5 & $0 \cdot 5$ \\
\hline
\end{tabular}

${ }^{*}$ The final follow up interval for each tumour type includes the whole period of risk beyond the entry year for that specific follow up tA Poisson one tailed probability less than $0 \cdot 0005$ is reported as $0 \cdot 000$.

$\ddagger \quad(\mathrm{O}-\mathrm{E}) 100$

person years at risk 
When cure was not identified in the above sense, the excess number of deaths (observed minus expected) divided by the person years at risk and multiplied by 100 provided a measure of excess mortality that was compared for different tumour types. This measure was interpreted as the extra number of deaths occurring among each 100 survivors per year.

The different tumour types were considered by taking account of both survival beyond three years and a comparison of observed and expected mortality from all causes.

\section{LEUKAEMIA}

Acute lymphocytic leukaemia

Just over $60 \%$ of children who had survived at least three years were alive 10 years later (see table 1). Boys who had survived at least three years experienced lower subsequent survival than girls (fig 1). Although there was still an excess of deaths among survivors after 10 years' survival, it was only about one extra death per 100 survivors per year.

\section{LYMPHOMAS}

Survival beyond three years was greater after nonHodgkin lymphomas than after Hodgkin's disease (see table 1). Survival from three years, after Hodgkin's disease, was greater among children diagnosed more recently and when younger (see table 2 and fig 1). The excess mortality among children surviving at least 10 years from Hodgkin's disease was under one extra death per 100 survivors per year; 10 year survivors of non-Hodgkin lymphomas showed evidence of cure (see table 3 ).

\section{EMBRYONAL TUMOURS}

Neuroblastoma (including ganglioneuroblastoma) Survival beyond three years was substantially greater among children who had been diagnosed when younger (see table 2 and fig 2). Among those who had survived at least 10 years the excess mortality was less than one extra death per 200 survivors per year.

\section{Wilms' tumour}

Survival after three years was greater among children diagnosed more recently and among those diagnosed when younger (see table 2 and fig 2). The excess mortality among those who had survived at least five years was always less than one extra death per 200 survivors per year (see table 3 ).

\section{Retinoblastoma}

This tumour occurs in two forms: 'genetic' defined here as either bilateral disease or unilateral with another affected family member; 'non-genetic' is defined as unilateral with no known family history of the disease. Fig 2 includes a comparison of survival

\begin{tabular}{|c|c|c|c|c|c|c|c|c|c|c|c|}
\hline \multirow{3}{*}{$\begin{array}{l}\text { Poisson } \\
\text { probability } \\
(p) \dagger\end{array}$} & \multirow{3}{*}{$\begin{array}{l}\text { Excess } \\
\text { mortality } \neq\end{array}$} & \multicolumn{5}{|c|}{$10-19(\text { or } 10-)^{*}$} & \multicolumn{5}{|l|}{$20-$} \\
\hline & & \multirow{2}{*}{$\begin{array}{l}\text { No of } \\
\text { survivors }\end{array}$} & \multicolumn{2}{|l|}{ Deaths } & \multirow{2}{*}{$\begin{array}{l}\text { Poisson } \\
\text { probability } \\
(p) \dagger\end{array}$} & \multirow{2}{*}{$\begin{array}{l}\text { Excess } \\
\text { mortality } \neq\end{array}$} & \multirow{2}{*}{$\begin{array}{l}\text { No of } \\
\text { survivors }\end{array}$} & \multicolumn{2}{|l|}{ Deaths } & \multirow{2}{*}{$\begin{array}{l}\text { Poisson } \\
\text { probability } \\
(p)^{+}\end{array}$} & \multirow{2}{*}{$\begin{array}{l}\text { Excess } \\
\text { mortality } \neq\end{array}$} \\
\hline & & & $\begin{array}{l}\text { Observed } \\
(O)\end{array}$ & $\begin{array}{l}\text { Expected } \\
(E)\end{array}$ & & & & $\begin{array}{l}\text { Observed } \\
(O)\end{array}$ & $\begin{array}{l}\text { Expected } \\
(E)\end{array}$ & & \\
\hline 0.000 & $4 \cdot 6$ & 801 & 29 & $1 \cdot 2$ & 0.000 & $1 \cdot 1$ & & & & & \\
\hline 0.000 & $3 \cdot 2$ & 479 & 25 & $2 \cdot 1$ & 0.000 & 0.8 & 133 & 6 & $1 \cdot 1$ & 0.001 & 0.6 \\
\hline 0.000 & 1.7 & 291 & 2 & 1.5 & 0.430 & 0.0 & 127 & 1 & $1 \cdot 1$ & 0.675 & 0.0 \\
\hline 0.000 & $1 \cdot 1$ & 292 & 9 & 1.0 & 0.000 & 0.4 & 151 & 4 & $0 \cdot 6$ & 0.003 & 0.4 \\
\hline 0.000 & 0.4 & 633 & 9 & $2 \cdot 0$ & 0.000 & 0.2 & 220 & 7 & $1 \cdot 1$ & 0.000 & 0.4 \\
\hline 0.000 & 0.9 & 324 & 15 & $1 \cdot 2$ & 0.000 & 0.5 & 188 & 4 & $1 \cdot 2$ & 0.037 & 0.2 \\
\hline $1 \cdot 000$ & 0.0 & 403 & 3 & 1.5 & $0 \cdot 190$ & 0.0 & 190 & 1 & 1.6 & 0.790 & $0 \cdot 0$ \\
\hline 0.000 & $5 \cdot 6$ & 197 & 21 & $1 \cdot 3$ & 0.000 & $1 \cdot 1$ & & & & & \\
\hline 0.000 & $3 \cdot 0$ & 151 & 18 & 0.9 & 0.000 & 1.4 & & & & & \\
\hline $0 \cdot 000$ & $1 \cdot 2$ & 379 & 26 & $1 \cdot 5$ & 0.000 & 1.0 & 135 & 1 & 0.7 & 0.495 & $0 \cdot 0$ \\
\hline 0.000 & $1 \cdot 8$ & 498 & 35 & $2 \cdot 1$ & 0.000 & 0.9 & 230 & 13 & 1.5 & 0.000 & 0.8 \\
\hline 0.000 & $2 \cdot 1$ & 103 & 5 & 0.8 & 0.001 & 0.4 & & & & & \\
\hline 0.000 & $1 \cdot 2$ & 184 & 4 & $1 \cdot 0$ & $0 \cdot 018$ & $0 \cdot 2$ & 117 & 2 & 0.7 & $0 \cdot 158$ & 0.2 \\
\hline 0.000 & 1.5 & 126 & 3 & $0 \cdot 6$ & 0.022 & $0 \cdot 3$ & & & & & \\
\hline 0.551 & 0.0 & & & & & & & & & & \\
\hline $0 \cdot 000$ & 0.4 & & & & & & & & & & \\
\hline
\end{tabular}



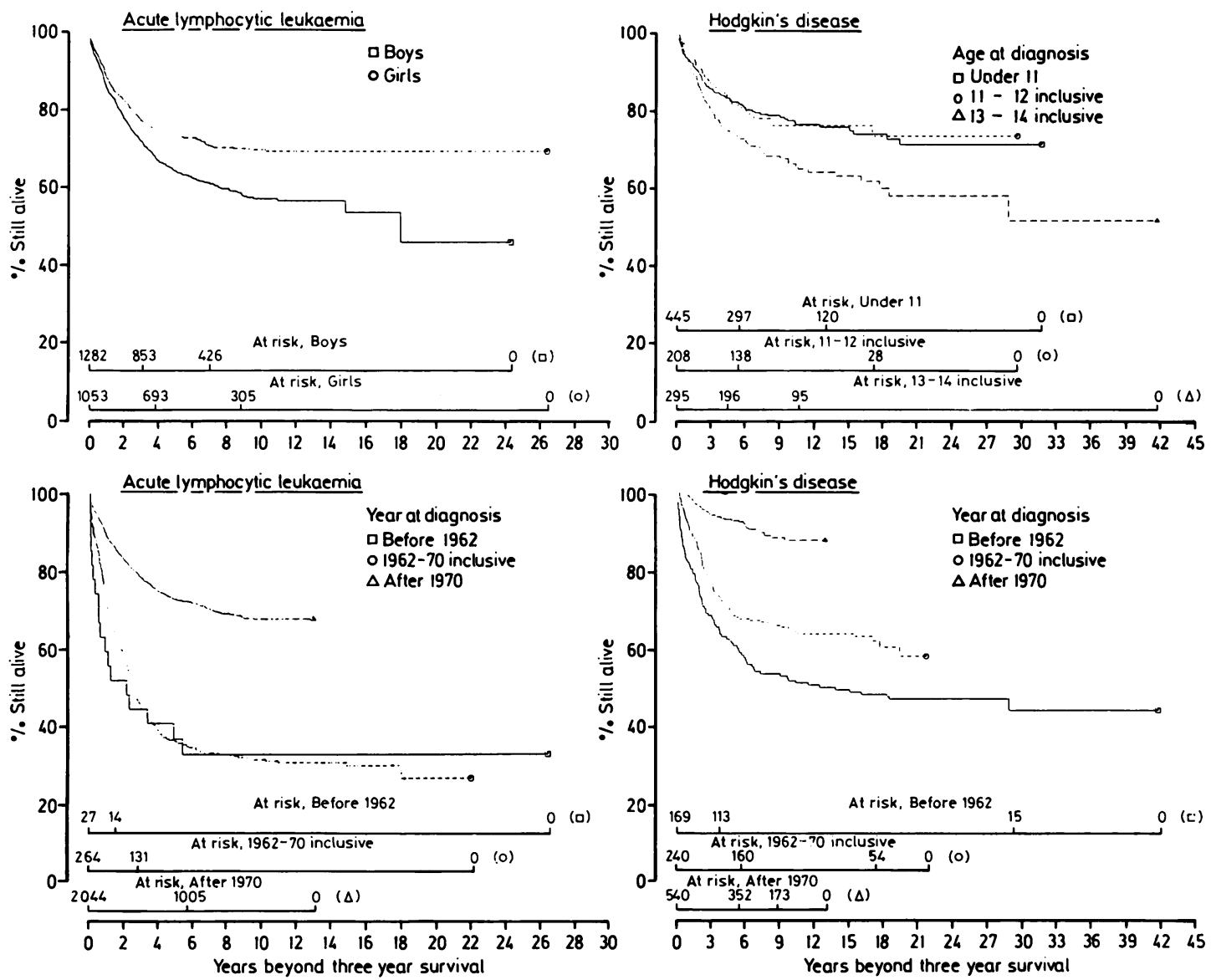

Fig 1 Long term survival after acute lymphocytic leukaemia and Hodgkin's disease.

subsequent to three years after genetic and nongenetic retinoblastoma. Those who had survived at least three years after retinoblastoma showed evidence of cure, but there was evidence of continuing excess mortality among survivors of genetic retinoblastoma.

TUMOURS OF THE CENTRAL NERVOUS SYSTEM

Survival subsequent to three years improved among those diagnosed more recently with medulloblastoma, ependymoma, and other astrocytomas. Survival from three years was also greater among those diagnosed when older with ependymoma, juvenile astrocytoma, and other astrocytomas, in contrast with greater survival for those diagnosed when younger with medulloblastoma (see table 2 and fig 3).
The excess mortality after medulloblastoma decreased from 13 extra deaths per 100 survivors per year, at three and four years from diagnosis, to around one extra death beyond 10 years. The excess mortality among those who survived at least three years after juvenile astrocytoma was always less than two extra deaths per 100 survivors per year.

\section{MALIGNANT BONE TUMOURS}

\section{Osteosarcoma}

The excess mortality among survivors decreased from about eight extra deaths per 100 survivors per year among those who had survived at least three or four years, to approximately one extra death per 200 survivors per year among those surviving at least 10 years. 

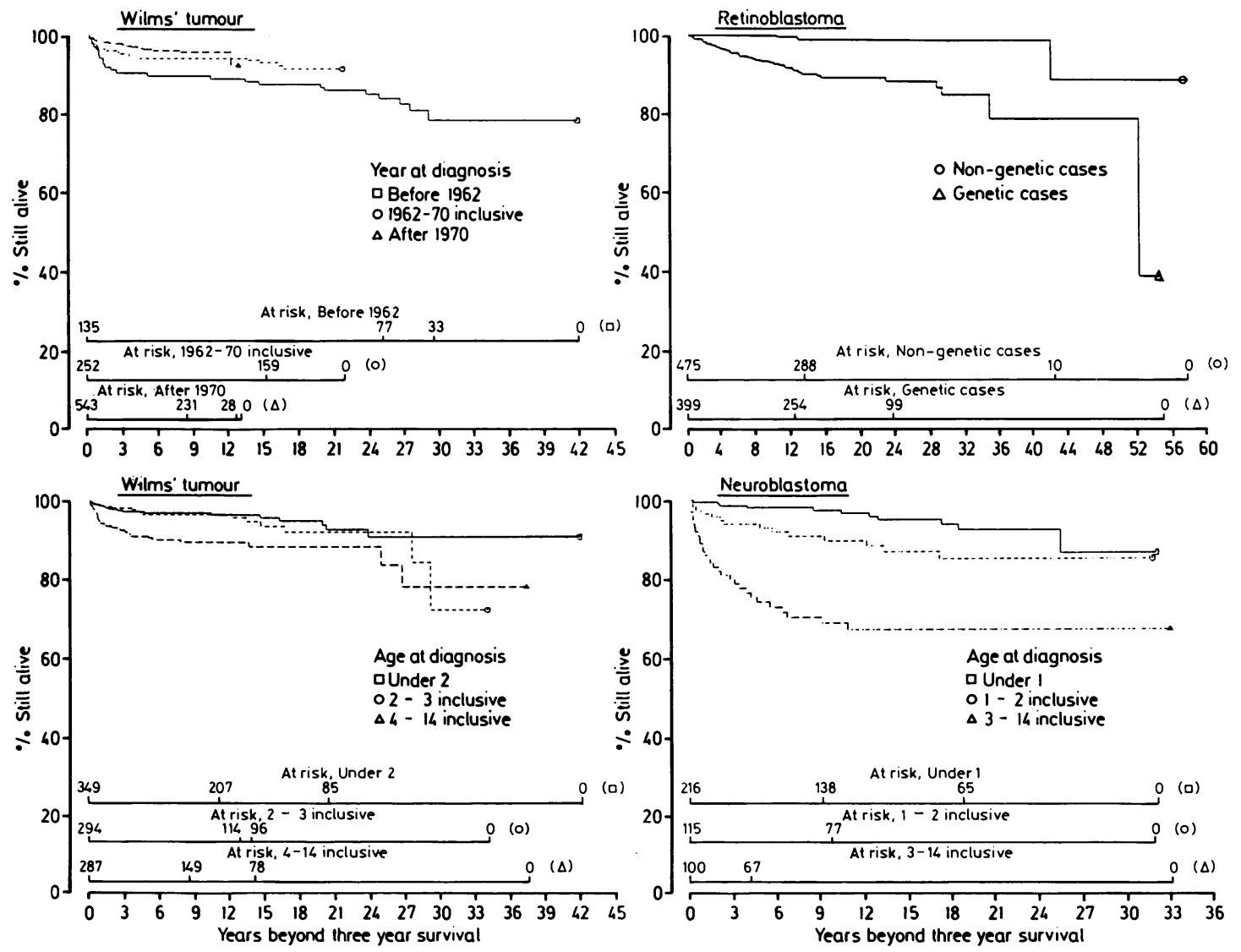

Fig 2 Long term survival after Wilms' tumour, retinoblastoma, and neuroblastoma.

\section{Ewing's tumour}

The excess mortality among survivors was high at three and four years from diagnosis at around 18 extra deaths per 100 survivors per year but this decreased to under three extra deaths among those surviving at least five years.

\section{SOFT TISSUE SARCOMA}

\section{Fibrosarcoma}

The survival prospects beyond three years have been good for many years. The excess mortality was under one extra death per 200 survivors per year among 10 year survivors.

\section{Rhabdomyosarcoma}

Survival beyond three years was slightly poorer than for fibrosarcoma (see table 1). Survival was better for boys than girls. Ten years from three year survival $87 \%$ of boys and $74 \%$ of girls were still alive. The excess mortality among those who survived at least 10 years was similar to that observed for fibrosarcoma.

MALIGNANT GONADAL GERM CELL TUMOURS

Survival beyond three years was about $95 \% 10$ years later for both malignant testicular and ovarian germ cell tumours. Survival subsequent to three years for ovarian tumours improved substantially among those diagnosed more recently. Ten years from three year survival $88 \%, 91 \%$, and $98 \%$ of those diagnosed before 1962, between 1962 and 1970, and after 1970 are still alive respectively. Excess mortality among children who had survived at least three years after either a testicular or ovarian tumour was under two extra deaths per 100 survivors per year. 

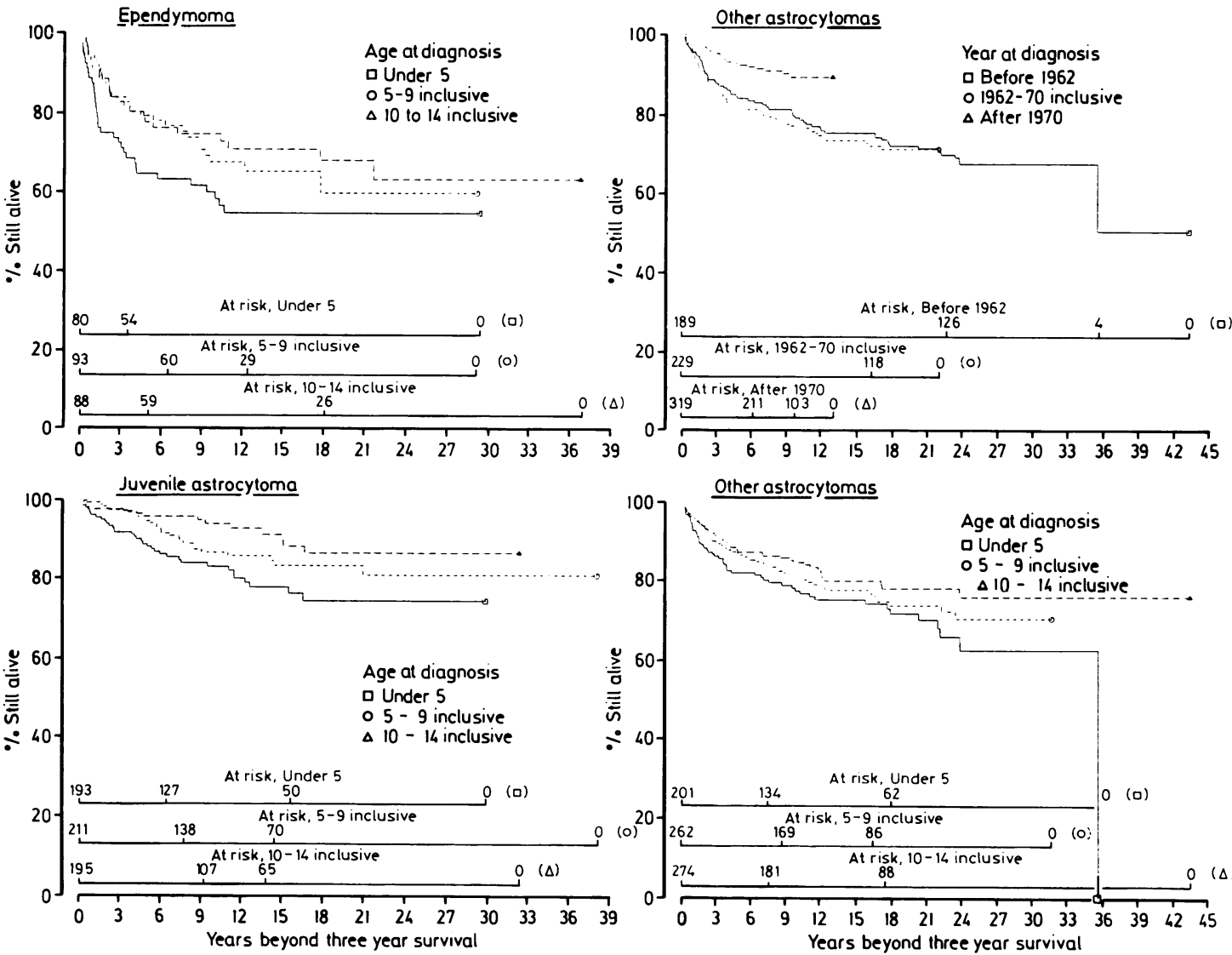

Fig 3 Long term survival after childhood tumours of the central nervous system.

\section{Discussion}

With few exceptions ${ }^{2} 78$ information available on survival after childhood cancer arises either from particular series of cases that are not population based, or from randomised clinical trials. Furthermore, survival is usually examined only in the years immediately after diagnosis. The present study was broadly population based, including the great majority of childhood cancers occurring in Britain. Therefore sufficient cases were available to attempt to examine long term survival and curability in a reliable way. Data were included that relate to survivors diagnosed mostly between 1960 and 1981 and therefore an appreciation of changes in long term survival over time could be obtained. No examination of the effects of treatment was attempted but the considerable improvement in survival subsequent to three years observed for many tumours in more recent years was almost certainly a direct consequence of improved treatment.

No attempt was made to examine the specific causes of death among those who had survived at least three years. The method of assessing evidence of cure compares observed mortality among survivors with that expected from the general population. When there was no statistical evidence of a difference between observed and expected mortality among survivors they were considered cured. Investigators studying evidence concerning the curability of adult cancer have encountered a problem with this method. It has been shown that survivors of several adult cancers including cancer of the breast, cervix uteri, corpus uteri, and ovary may experience similar mortality, from all causes, to that expected from the general population and yet still experience an excess 

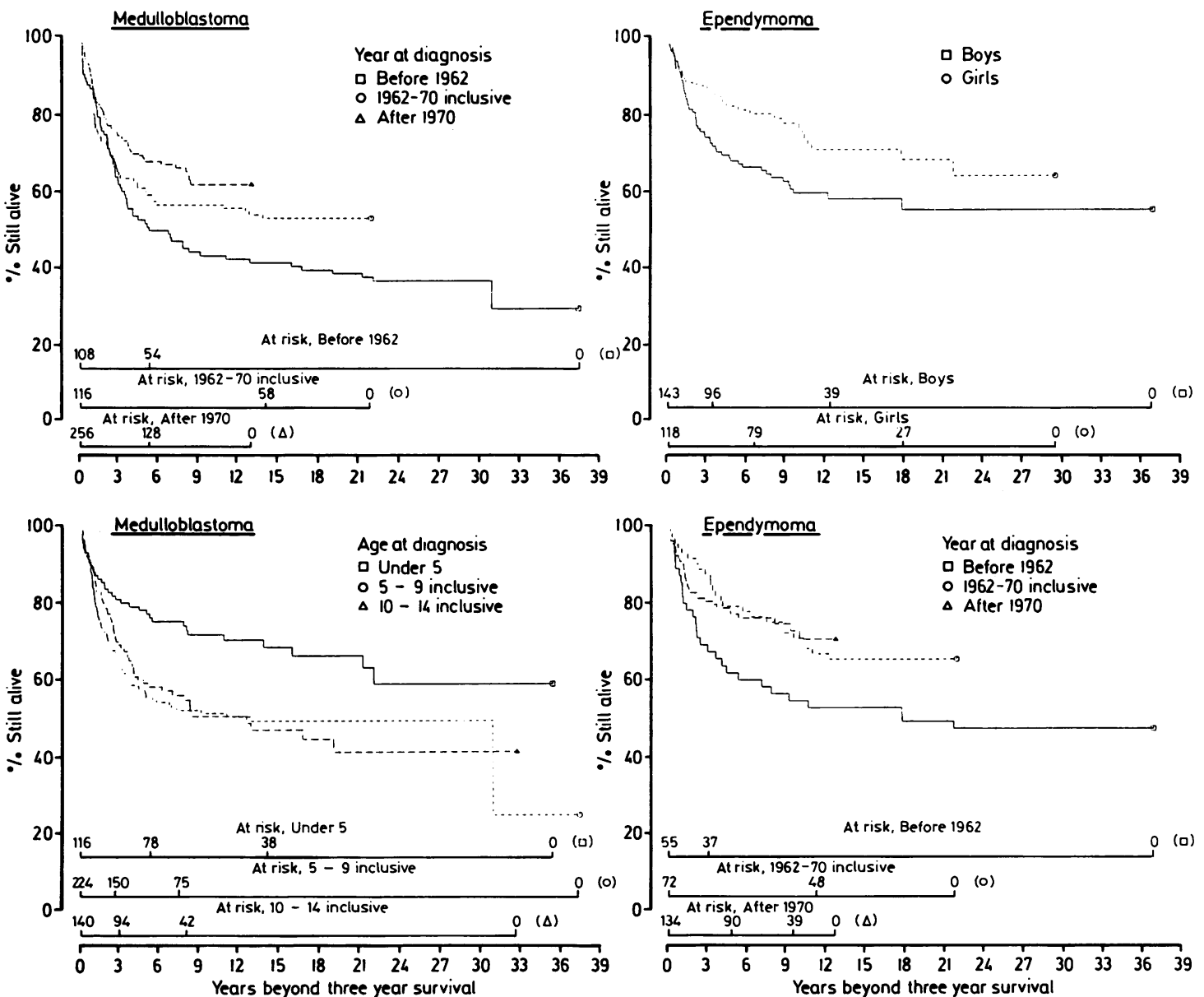

of deaths from the original cancer when compared with the general population. ${ }^{910}$ Other work indicates it is very unlikely that this excess is an artefact of death certification. ${ }^{11}$ Therefore our statistical definition of cure may not be the same as clinical cure ${ }^{10}$ It is now well established that survivors of childhood cancer experience a greater risk of a subsequent tumour than expected on the basis of rates of malignant disease occurring in the general population. ${ }^{12}$ Therefore an absence of evidence for cure in the statistical sense defined above could arise through an excess of causes other than recurrent tumour and as a result we may underestimate the numbers cured in the clinical sense of absence of recurrent tumour. These possible problems will be considered in a separate paper concentrating on the specific causes of death.

Initially, it is important to examine long term survival, and to compare observed and expected mortality among survivors from all causes of death. This will provide a provisional understanding of the curability of various tumours and the magnitude of any excess mortality in the absence of evidence for cure.

A previous attempt to examine long term survival and cure after childhood cancer, based on substantially fewer cases than available for the present analysis, reported that survivors of several types of childhood tumour experience an excess of mortality when compared with the general population and that an excess persists for at least 20 years from diagnosis for some tumours. ${ }^{13}$ In our data survival subsequent to three years improved substantially for acute lymphocytic leukaemia, Hodgkin's disease, and medulloblastoma. Less striking but important improvements have also occurred after Wilms' 


\section{Hawkins}

tumour, ependymoma, other astrocytomas, and malignant ovarian germ cell tumours. The decline in mortality from a range of childhood tumours has been reported from the United States ${ }^{14}$ and Italy. ${ }^{15}$

Some of the most interesting comparisons between observed and expected mortality occur more than a decade after diagnosis, where the numbers became rather small, and as a result previous studies were at a serious disadvantage. Although we have relatively large numbers of cases available for analysis there is still a danger of concluding that there is no real difference, because a difference between observed and expected mortality is not significant, when in fact the statistical power of the comparison is low within that particular follow up interval because of a small number of expected deaths. To reduce the possibility of such spurious interpretations the final follow up intervals in table 3 , and in any other results reported, have at least 100 survivors still at risk on entry. Evidence of cure is only examined when the expected number of deaths beyond a specified follow up time is at least two. This gives an $80 \%$ probability of detecting a mortality rate fourfold that expected using a 5\% (one sided) significance level.

Long term survival after the embryonal tumours was always very good in that at least about $90 \%$ of three year survivors were alive 10 years later. It has been reported from the United States that over $90 \%$ of those surviving at least five years from these embryonal tumours survive a further 10 years. ${ }^{16}$ The excess mortality among those surviving at least 10 years after an embryonal tumour never exceeds one extra death per 200 survivors per year. Many of the deaths that occur between five and 20 years from diagnosis of genetic retinoblastoma are likely to be caused by second primary tumours and therefore these are, at least partially, responsible for excess mortality. Late recurrence of neuroblastoma and Wilms' tumour, although rare, have been reported previously. ${ }^{17} 18$

The soft tissue sarcomas were another group with good long term prospects. This is in broad agreement with over $90 \%$ of those surviving at least five years remaining alive 10 years later in a study carried out in the United States. ${ }^{16}$

There is a difference in the long term prospects after Hodgkin's disease and non-Hodgkin lymphomas. Ten year survivors of non-Hodgkin lymphomas show evidence of cure, in contrast to those surviving at least 10 years after Hodgkin's disease who experience between one and two extra deaths per 200 survivors per year. It has previously been reported that of those surviving at least five years, $65 \%$ of those with Hodgkin's disease, and $90 \%$ of those with non-Hodgkin lymphomas were alive 10 years later, based on individuals treated in the United States. ${ }^{16}$

Long term prospects after tumours of the central nervous system vary considerably depending on the type of tumour. At 10 years from three year survival only just over half of those diagnosed with medulloblastoma were still alive, in contrast with almost $90 \%$ of those diagnosed with juvenile astrocytoma. Survivors of each central nervous system tumour considered, except medulloblastoma, experienced improved survival subsequent to three years if they were diagnosed when older. In common with neuroblastoma, Wilms' tumour, and Hodgkin's disease survival beyond three years is greater among those diagnosed when younger with medulloblastoma.

Average follow up times after acute leukaemia are still relatively short as these diseases were almost always fatal before the introduction of modern forms of treatment around 1970. Therefore more follow up is needed before a firm assessment of the long term prognosis may be made. Children who had survived at least 10 years after acute lymphocytic leukaemia experienced an excess mortality of just over one extra death per 100 survivors per year. It has previously been suggested that a greater proportion of females with acute lymphocytic leukaemia are cured than are males. ${ }^{19}$ In our data the excess death rates were consistently greater among the male survivors.

\section{Conclusion}

After surviving three years, survival prospects are generally very good in that, for most of the childhood tumours considered, over $80 \%$ of those surviving at least three years were alive 10 years later. Of the remainder there have been substantial improvements in survival beyond three years after acute lymphocytic leukaemia, Hodgkin's disease, medulloblastoma, and ependymoma where the percentage alive 10 years later among those diagnosed since 1970 are $68 \%, 87 \%, 62 \%$, and $73 \%$ respectively. This leaves only osteosarcoma and Ewing's tumour where survival subsequent to three years is static at around $77 \%$ and $57 \%$ alive 10 years later respectively.

Comparing mortality among survivors with that expected showed evidence of cure among survivors of non-Hodgkin lymphomas and non-genetic retinoblastoma. Survivors of other tumours, with sufficient cases surviving beyond 10 years to assess excess mortality, may be considered in two groups. Firstly, those who had survived at least 10 years after neuroblastoma, Wilms' tumour, genetic retinoblastoma, osteosarcoma, fibrosarcoma, or rhabdomyosarcoma never experienced an excess mortality exceeding one extra death per 200 survivors per year. 
Secondly, those who had survived at least 10 years after acute lymphocytic leukaemia, Hodgkin's disease, or a tumour of the central nervous system experienced an excess mortality of about one extra death per 100 survivors per year. The excess mortality in both groups was therefore gratifyingly small, particularly among survivors in the former group. The excess mortality among the latter group was similar to that experienced by female survivors of breast cancer subsequent to a recurrence free survival of 15 years. ${ }^{9}$

It is important to continue to monitor the mortality of survivors of childhood cancer for two main reasons: firstly, to examine their mortality when they enter middle age where expected mortality increases; and secondly, to examine long term survival after recently introduced combined forms of treatment for which, as yet, there is a relatively short follow up.

I sincerely thank Michael Potok, Elizabeth Mowat, David Winter, and Joanne Sturdy for their help with the present work. I am also grateful to Gerald Draper and Rupert Smith for their comments on early drafts of the manuscript, and to Drs LM Kinnier Wilson and JE Kingston for advice on the interpretation of medical information.

Particular thanks to the members of the Long-Term Follow-up Study Working Party (Professor DG Harnden, Professor JS Malpas, Dr JR Mann, Professor HB Marsden, Dr PH Morris Jones, and Dr D Pearson) for their advice and support on this study and also thanks to them, and many other consultants, for access to medical records relating to their patients.

The Long-Term Follow-up Study is supported by the Cancer Research Campaign and the Leukaemia Research Fund. The Childhood Cancer Research Group is supported by the Department of Health and the Scottish Home and Health Department.

The work would be impossible without the help of the Office of Population Censuses and Surveys (particularly the National Health Service Central Registers), the Information Services Division of the Common Services Agency of the Scottish Health Service, the Registrar General for Scotland, and the regional cancer registries in providing copies of notifications of childhood cancer cases.

\section{References}

${ }^{1}$ Stiller CA. Descriptive epidemiology of childhood leukaemia and lymphoma in Great Britain. Leuk Res 1985;9:671-4.
${ }^{2}$ Draper GJ, Birch JM, Bithell JF, et al. Childhood cancer in Britain-incidence, survival and mortality. London: HMSO. Office of Population Censuses and Surveys, 1982. (Studies on Medical and Population Subjects, No 37).

${ }^{3}$ Birch JM, Marsden HB. A classification scheme for childhood cancer. Int J Cancer 1987;40:620-4.

4 Parkin DM, Stiller CA, Bieber A, et al. International incidence of childhood cancer. IARC Sci Publ 1988: No 87.

${ }^{5}$ Peto R, Pike MC, Armitage P, et al. Design and analysis of randomized clinical trials requiring prolonged observation of each patient. $\mathrm{Br} J$ Cancer 1977;35:1-39.

6 Stiller CA, Draper GJ. Trends in childhood leukaemia incidence in Britain 1968-78. Br J Cancer 1982;45:543-51.

7 Birch JM, Marsden HB, Morris Jones PH, et al. Improvements in survival from childhood cancer: results of a population based survey over 30 years. Br Med J 1988;296:1372-6.

${ }^{8}$ Stiller CA, Draper GJ. Treatment centre size, trial entry and survival in acute lymphoblastic leukaemia. Arch Dis Child 1989;64:657-61.

${ }^{9}$ Langlands AO, Pocock SJ, Kerr GR, Gore SM. Long-term survival of patients with breast cancer: a study of the curability of disease. Br Med J 1979;ii:1247-51.

${ }^{10}$ Haybittle JL, Kingsley-Pillers EM. Long-term survival experience of female patients with genital cancer. $B r J$ Cancer 1988;57: 322-5.

11 Brinkley D, Haybittle JL, Alderson MR. Death certification in cancer of the breast. Br Med J 1984;289:465-7.

12 Hawkins MM, Draper GJ, Kingston JE. Incidence of second primary tumours among childhood cancer survivors. $\mathrm{Br} J$ Cancer 1987;56:339-47.

13 Taylor DD, Potish RA. Late deaths following radiotherapy for paediatric tumours. Am J Clin Oncol 1985;8:472-6.

14 Miller RW, McKay FW. Decline in US childhood cancer mortality: 1950 through 1980. JAMA 1984;251:1567-70.

15 La Vecchia C, Decarli A. Decline in childhood cancer mortality in Italy, 1955-1980. Oncology 1988;45:93-7.

${ }^{16} \mathrm{Li}$ FP, Myers MH, Heise HW, Jaffe N. The course of five-year survivors of cancer in childhood cancer. Pediatrics 1978;93: $185-7$.

17 Richards MJS, Joo P, Gilbert EF. The rare problem of late recurrence in neuroblastoma. Cancer 1976;38:1847-52.

${ }^{18}$ Kim TH, Zaatari GS, Baum ES, et al. Recurrence of Wilms' tumour after apparent cure. Pediatrics 1985;107:44-9.

19 George SL, Aur RJA, Mauer AM, Simone JV. A reappraisal of the results of stopping therapy in childhood leukaemia. $N$ Engl $J$ Med 1979;300:269-73.

Correspondence to Dr MM Hawkins, Childhood Cancer Research Group, Radcliffe Infirmary, Woodstock Road, Oxford OX2 6HE.

Accepted 24 November 1988 